\title{
TEXTURA DO SOLO: IMPORTÂNCIA DA REALIZAÇÃO DE ATIVIDADES PRÁTICAS NO ENSINO DE GEOGRAFIA
}

\section{Soil Texture: Importance of Practical Activities in Geography Teaching}

\author{
Guilherme Amisterdan Correia Lima \\ Graduando no Departamento de Geografia da Universidade Estadual da Paraíba \\ amisterdan87@gmail.com \\ Poliana Mariano Araújo \\ Graduanda no Departamento de Geografia da Universidade Estadual da Paraíba \\ poli-ana@hotmail.com \\ Lediam Rodrigues Lopes Ramos Reinaldo \\ Profa. Adjunta do Departamento de Geografia da Universidade Estadual da Paraíba \\ lediam@ig.com.br \\ Rafael Albuquerque Xavier \\ Prof. do Departamento de Geografia da Universidade Estadual da Paraíba \\ xavierra@uol.com.br
}

Artigo recebido em 26/02/2015 e aceito para publicação em 17/07/2015

DOI: $10.12957 / \operatorname{tamoios} .2015 .15318$

Resumo

Abstract
A abordagem atual da geografia tem despertado o interesse por novas práticas e ações que insiram os alunos em seu cotidiano, possibilitando a compreensão e a leitura do espaço em que vivem. O presente trabalho, objetiva relatar a experiência desenvolvida com os alunos do $4^{\circ}$ período do curso de licenciatura plena em geografia da Universidade Estadual da Paraíba - UEPB e os alunos da Escola Municipal Eduardo Medeiros, localizada no município de Serra Redonda, interior da Paraíba. Tomado como base a Experimentoteca de Solos desenvolvida pelo projeto de extensão Solo na Escola do Departamento de Solos e Engenharia Agrícola da UFPR, realizou-se algumas ações em sala de aula que permitiram aos estudantes, desenvolverem os seus conhecimentos a respeito dos elementos que compõe o solo e a sua textura. A realização de práticas experimentais no ensino de geografia é uma atividade importante, pois permite aos professores, utilizarem novas abordagens que poderão ser utilizadas em sala de aula estendendo-se ao cotidiano do aluno, permitindo que estes também desenvolvam as suas habilidades

Palavras-chave: Geografia; Práticas Educativas; Ensino de Solos.

The current approach to Geography has been attracted the interest for new practices and actions that insert students in their daily life, allowing both comprehension and reading of their living space. The main objective of the present work is to report the experience developed with undergraduate students in the fourth semester of Geography from the State University of Paraíba - UEPB - and students from the City School Eduardo Medeiros, located in Serra Redonda, interior of Paraíba. Taking the "Experimentoteca de Solos" developed by the extension project "Soil in the School" of the Soil Department and Agricultural Engineering of UFPR as the basis, some actions were performed inside the classrooms in order to help students to increase their knowledge regarding to soil components and its texture. The use of experimental practices in Geography teaching is an important activity, since it allows teachers to employ new approaches that can be useful in both inside and outside the classroom, which permits students to expand their skills.

Key-words: Geography; Educational Practices; Teaching Soils. 


\section{INTRODUÇÃO}

A abordagem atual da geografia vem desenvolvendo novas práticas e ações que insiram o aluno no seu cotidiano, possibilitando a compreensão e a leitura do mundo em que vivem. Porém, uma das grandes deficiências no ensino dessa disciplina, é a dificuldade de abordar alguns conteúdos que são apontados como difíceis, baseando-se apenas em aulas expositivas e sem atividades práticas. Sabe-se que a geografia está interligada com as demais ciências atuando na produção do conhecimento para além do âmbito escolar. Devido à ineficiência de alguns professores muitos conteúdos são ensinados separadamente, elementos de categorias físicas dissociados dos elementos humanos, como se ambos não tivessem uma relação entre si. Nota-se ainda que alguns livros didáticos trazem informações descontextualizadas, distante da realidade dos alunos, construindo os estereótipos de que a disciplina não tem utilidade para a vida dos que com ela convivem. Pode-se dizer que o ensino do solo na escola é pouco valorizado devido à seleção dos assuntos do currículo escolar a serem ensinado os quais se tornam limitando pelos professores. Porem, os docentes devem ter posicionamentos de educador compromissado em formar cidadãos defensores do direito de viver em um ambiente melhor. Pois o solo é um recurso natural indispensável para a produção de alimentos -garantindo a vida- possibilita grandes construções na sociedade entre outras infinidades. Esta é a razão pela qual se deve ensinar solo em todos os níveis, desde o fundamental ao superior e grupos de pesquisas para saber, O que é solo? Para que preserva-lo? Assim, garantindo defensores do ambiente, ligando a teoria com a prática, ou seja, relação do que é ensinado para o que é vivido. Neste sentido estudar o solo nas aulas de geografia configura-se como uma necessidade, tendo em vista a sua importância para o equilíbrio dos ecossistemas e a manutenção da vida, ou seja, o equilíbrio ambiental e social. O solo é o constituinte responsável pelo crescimento das plantas, armazenamento de nutrientes, controle de fluxo de água, além de servir de habitat para as diversas espécies de seres vivos e controlar a circulação de carbono (C) na atmosfera. O presente trabalho, objetiva relatar a experiência desenvolvida com os alunos do $4^{\circ}$ período do curso de Licenciatura Plena em Geografia da Universidade Estadual da Paraíba - UEPB e os alunos da Escola Municipal Eduardo Medeiros, localizada no município de Serra Redonda, interior da Paraíba, referente ao estudo de solos e a importância das atividades práticas em sala de aula, permitindo uma melhor 
compreensão sobre os diferentes temas. A realização de atividades práticas constitui um importante meio de aprendizagem, visto que os alunos da licenciatura poderão reproduzi-las em sala de aula, contribuindo com um melhor aproveitamento do estudo de solos e os alunos das séries iniciais com uma melhor consciência da importância do solo para o ambiente e a sociedade.

\section{METODOLOGIA}

A metodologia utilizada no presente trabalho consiste na realização de uma atividade prática desenvolvida com estudantes em sala de aula e na elaboração de questionários com o objetivo de caracterizar os conhecimentos adquiridos pelos alunos após o termino da atividade a respeito dos elementos que estão presentes no solo, bem como, as noções de quantidade de materiais que possibilitam as suas diferentes texturas.

As ações desenvolvidas durante a experiência aconteceram em dois momentos. Primeiro, com os estudantes da Universidade Estadual da Paraíba - UEPB, alunos do curso de licenciatura em geografia que estavam iniciando o componente de Pedologia no $4^{\circ}$ semestre e no segundo momento, a ação aconteceu em uma escola municipal localizada na cidade de Serra Redonda interior da Paraíba, com os alunos do $3^{\circ}$ ano da primeira fase do ensino fundamental. Antes da realização das atividades práticas, foi dada uma aula expositiva a respeito dos elementos presentes na formação do solo e da sua importância para o equilíbrio do planeta, o objetivo era fazer os alunos apresentarem os seus conhecimentos em relação ao tema proposto, possibilitando ao final da atividade a verificação da aprendizagem dos alunos.

Tanto na Universidade quanto na escola, realizou-se uma atividade prática baseada na Experimentoteca de Solos de (Macanhão e Lima, 2005), desenvolvida no projeto de Extensão Universitária Solo na Escola da Universidade Federal do Paraná (UFPR). Durante o experimento, os alunos foram divididos em dois grupos que receberam os seguintes materiais:

Grupo 1 - dois copinhos (de café) com pedrinhas de até $6 \mathrm{~mm}$ de diâmetro, quatro copinhos com areia grossa (de construção), cinco copinhos com areia fina (de construção peneirada), um copinho com argila de modelar, previamente seca e triturada, dois copinhos com água e uma travessa de plástico, como podem ser vistos na Figura 1. 


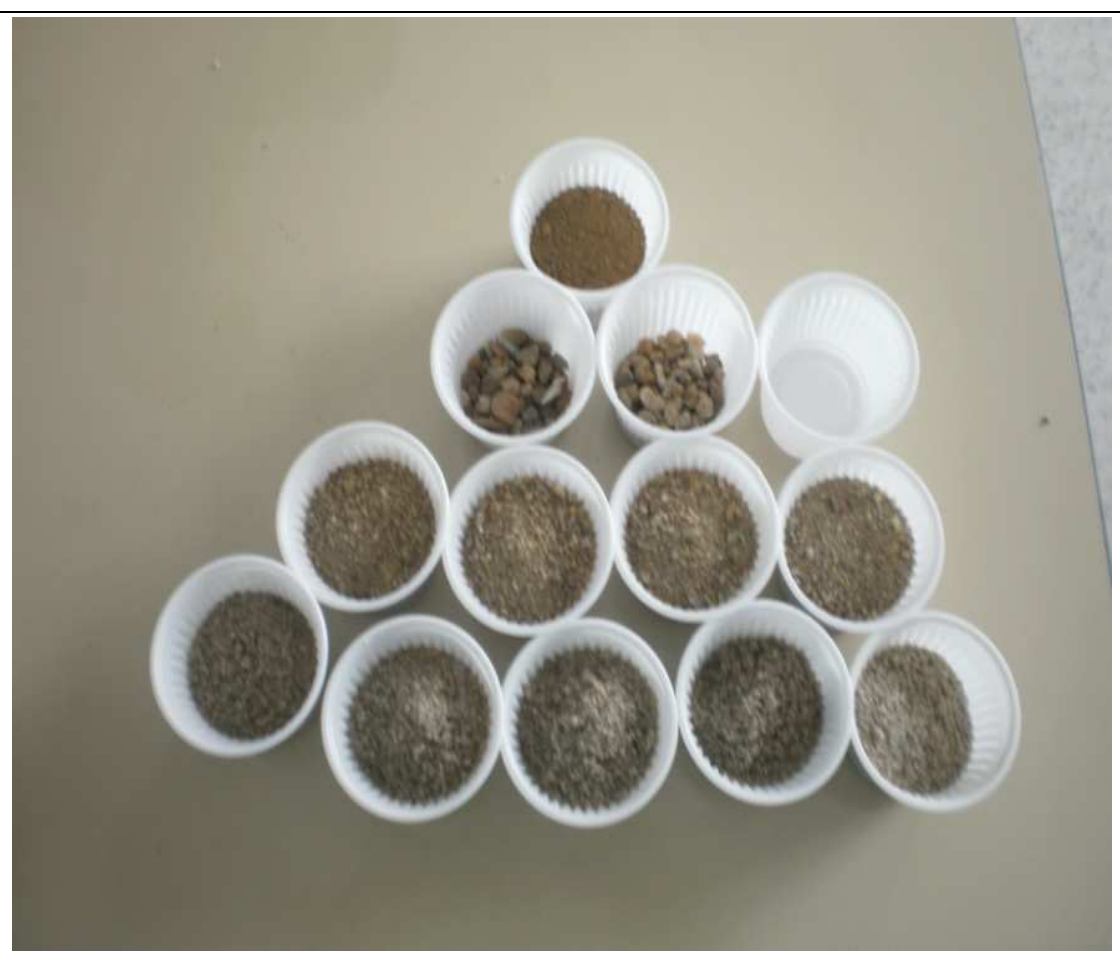

Fig. 1: materiais usados pelo grupo um. Fonte: atividade prática, 2014.

Grupo 2 - um copinho (também de café) com areia grossa (de construção), um copinho com areia fina (de construção peneirada), sete copinhos com argila de modelar, também previamente seca e triturada, dois copinhos com água e uma travessa de plástico (Figura 2) 


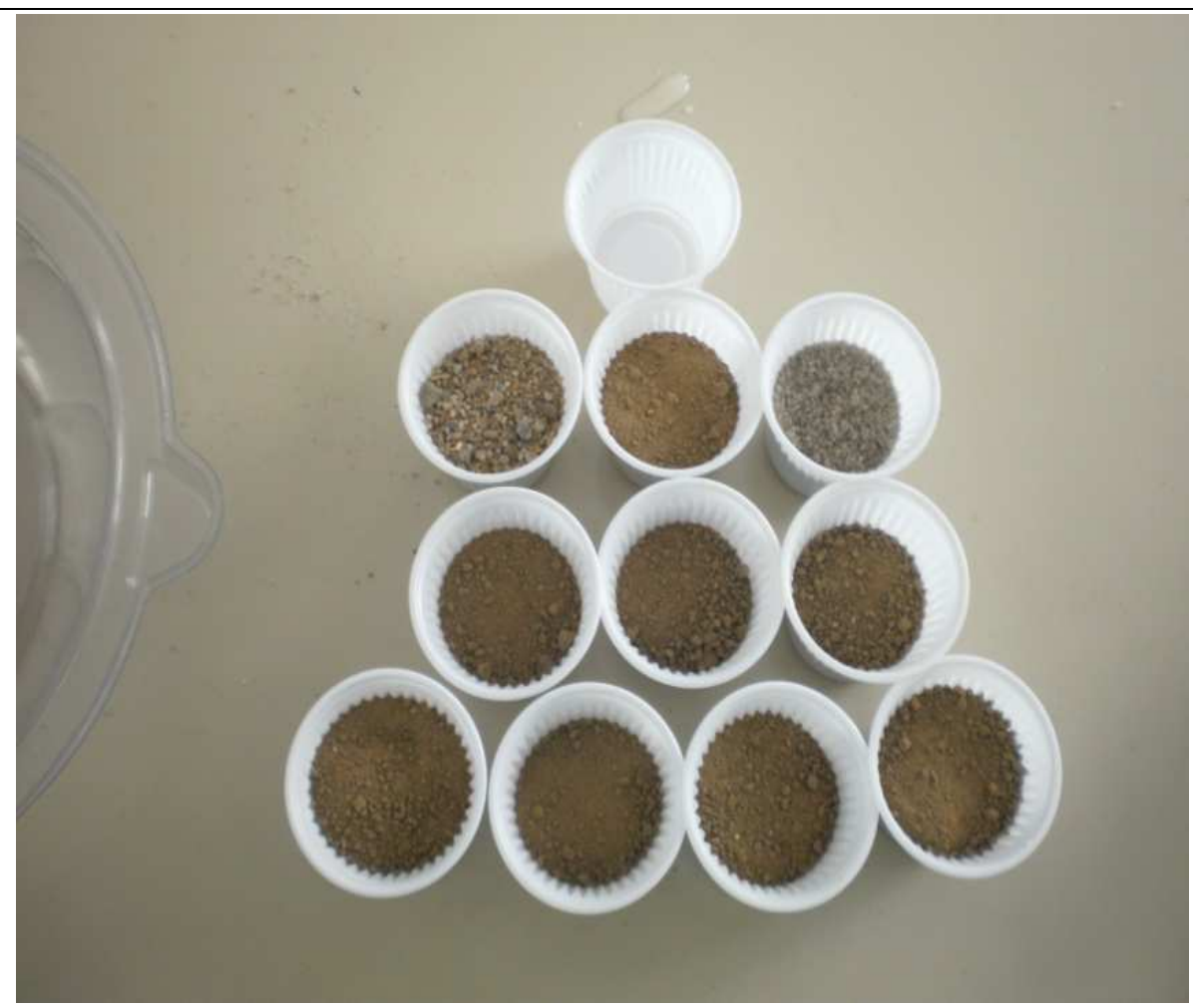

Fig.2: Materiais usados pelo grupo dois. Fonte: Atividade Prática, 2014.

O Objetivo da atividade prática era permitir que os alunos misturassem os elementos dentro da travessa de plástico, sendo cada grupo responsável por formar um tipo de solo diferente. O primeiro, um "solo" arenoso e o segundo um "solo" argiloso. Enquanto desenvolvia o experimento os estudantes foram orientados a sentirem por meio do tato a consistência e a sensação dos solos que estavam formando, bem como observar a quantidade dos elementos presentes na sua estrutura. Após o termino da atividade, os alunos foram questionados em relação ao que haviam aprendido, bem como, a importância das experiências práticas em sala de aula que possibilita uma melhor abordagem dos conteúdos.

\section{RESULTADOS E DISCUSSÃO}

A geografia escolar responsável por analisar as relações que envolvem natureza e sociedade, deve sugerir novas práticas de ensino, capaz de incluir os diferentes temas e conceitos ao contexto social dos alunos, com vista a uma prática reflexiva e inovadora. O fato é que muitos educadores não são capazes de relacionar o cotidiano com a sala de aula, fazendo o aluno reconhecer que está inserido em um espaço onde as diferentes 
ações podem modificar significativamente o ambiente. Persiste nos dias atuais, a ideia do professor como um mero reprodutor de conceitos prontos, ainda distantes de desenvolverem ações que despertem a criatividade e a atenção do aluno para os temas que são de fundamental importância ao conhecimento geográfico. Para Sacramento (2010, p. 5): “O papel atual da Geografia escolar é fazer com que o aluno compreenda os fenômenos geográficos especializados em seu cotidiano, permitindo-lhe localizar-se e perceber tais transformações”. Esse fato demonstra a importância do educador na busca por métodos que facilitem a aprendizagem do aluno, reduzindo as distâncias entre teoria e prática. $\mathrm{Na}$ atualidade muitas questões têm gerado importantes reflexões a respeito da problemática ambiental e dos diversos problemas que o uso inadequado do solo pode causar a biodiversidade, incluindo os seres humanos. Esse fato desperta a atenção para as práticas ecologicamente corretas em busca do desenvolvimento sustentável. Porém, no momento em que se ampliam as preocupações com a questão ambiental, o estudo do solo passa despercebido ou colocado em segundo plano nas aulas de geografia, em especial na educação básica onde o conteúdo é encarado como pouco importante por alguns professores, estes por não dominar com precisão o assunto ou porque se limita ao livro didático o qual apresenta pouco ou nada sobre solos. No entanto, os professores de geografia devem ressaltar para os alunos a importância do solo e a ligação direta com a sociedade. Sabe-se que este recurso está sendo degradado sem nenhuma preocupação dos problemas que vem sendo gerados, comprometendo a existência da biodiversidade e a degradação do meio ambiente, mesmo que o solo seja um recurso natural renovável ele precisará de mais de milhões de ano para se restituir. Isso significa que mesmo sendo um recurso renovável precisa ser utilizado de maneira que não comprometam sua qualidade. Cavalcanti $(2002$, p.17) afirma que: "a educação ambiental é aquela que se destina a fornecer instrumentos elementares para que os cidadãos possam enfrentar seu cotidiano com consciência e interatividade com seu ambiente". A autora quer dize que para que os alunos tenha melhor compreensão do conteúdo ensinado tenha relação com a vida deles, ou seja, o professor deve trabalhar o assunto partindo do lugar de vivência do alunado, intercalando o conhecimento científico com o conhecimento prévio que eles trazem consigo. Porém, para ensinar o tema solos despertando o interesse e melhorando o entendimento discente e o corpo docente deve-se posicionar como educador compromissado em formar cidadãos defensores do ambiente, assim, contribuindo para o verdadeiro desenvolvimento 
sustentável. A atividade prática realizada no curso de geografia com os alunos do $4^{\circ}$ período que estavam cursando o componente de Pedologia permitiu que os mesmos reconhecessem que o solo é formado por diversos elementos em diferentes quantidades, Além de diferenciar as texturas dos solos que foram produzidos. Como descrito na metodologia à turma foi dividida em dois grupos, que receberam os materiais e foram orientados a analisar a textura. O primeiro grupo após o contato por meio do tato, afirmou que a sensação sentida era de aspereza, enquanto o segundo, afirmou sentir a sensação de pegajosidade. Essas características apresentadas pelos alunos são explicadas pela presença de areia, silte e argila como os elementos básicos que constituem as texturas do solo e que na atividade foram colocadas propositalmente em diferentes quantidades, para que os mesmos fossem capazes de reconhecer e analisar essas características. Com os questionários aplicados logo após a atividade, ficou evidente que poucos alunos do curso de geografia, tiveram contato com práticas voltadas para o estudo de solos na fase escolar, o que contribuiu para o pouco conhecimento em relação à Pedologia. De acordo com o Curi et al, (1993, p.62): pedologia, 1-parte da ciência do solo que trata da origem, morfologia, distribuição, mapeamento e classificação dos solos, 2- Sinônimo de Ciência do solo, 3- Estudo do solo no seu habitat. Pode-se dizer que pedologia é a ciência que estuda o solo em sua gênese, forma e todos os espaços em que se encontra. Os 20 alunos que participaram da atividade prática na Universidade, possuem uma faixa etária entre 20 e 24 anos tendo finalizado o ensino médio nos anos de 2009 á 2011. Desses, 11 já tiveram alguma experiência com a sala de aula e seis possuem cursos técnicos na área de saúde, informática e mineração. Após serem questionados se durante a fase escolar os mesmos já havia realizado alguma experiência prática sobre estudo dos solos, 15 alunos responderam que não. Esse fato aponta para a ausência das atividades práticas na escola em relação a alguns temas que são importantes a educação e que muitas vezes passam despercebidos ou ignorados em sala de aula. Foi solicitado ainda, que os mesmos alunos apresentassem uma definição para solos. A resposta mais significativa foi: "produto da fragmentação das rochas", apesar de verdadeiro o conceito dado pelos estudantes, é importante ressaltar que o solo é bem mais que o produto da fragmentação das rochas, pois desempenha um conjunto de funções que são primordiais a manutenção dos ecossistemas terrestres e no equilíbrio atmosférico, participando ativamente do sequestro do carbono e outros gases que são nocivos à camada de ozônio. 
Assim, a realização de atividades práticas nos cursos de licenciatura constitui uma importante ferramenta de ensino, tendo em vista que os alunos serão professores da educação básica, podendo reproduzir o que lhe foi dado na universidade, de modo que contribua com uma aprendizagem cada vez mais significativa. Na escola a abordagem de temas fundamentais a geografia, ainda se deparam com algumas dificuldades, seja na falta de materiais didáticos como mapas, globos, argilas, massa de modelagem, entre outros. Esse fato faz alguns professores utilizarem apenas o livro didático como único recurso para o planejamento e a realização das aulas. Com o ensino de solos, não é diferente. O livro como único recurso tornam as aulas baseadas em leituras e escritas sobre o tema. A verdade é que o livro didático não deixa de ser um importante recurso que deve ser utilizado pelos professores, mas o seu uso repentino sem a utilização de outros meios acaba dando lugar para o que Oliveira (2001), denomina "indústria do livro didático", onde o professor não dispõe de alternativas em relação a materiais, reproduzindo o livro como um manual de instruções. A atividade prática em relação à textura do solo também foi desenvolvida na escola com uma turma de 18 alunos de faixa etária entre 08 e 12 anos que estavam cursando o $3^{\circ}$ ano do ensino fundamental I. Assim como na universidade, os alunos da escola também foram capazes de apreciar a consistência de cada tipo de solo que estavam formando, bem como, a compreensão de que os solos apresentam diferentes características e formações diferentes, podendo um ser mais propicio ao desenvolvimento de determinados cultivos em relação a outro. Os alunos foram capazes de formar em equipes os diferentes tipos de solos como podem ser vistos na figura 3. 


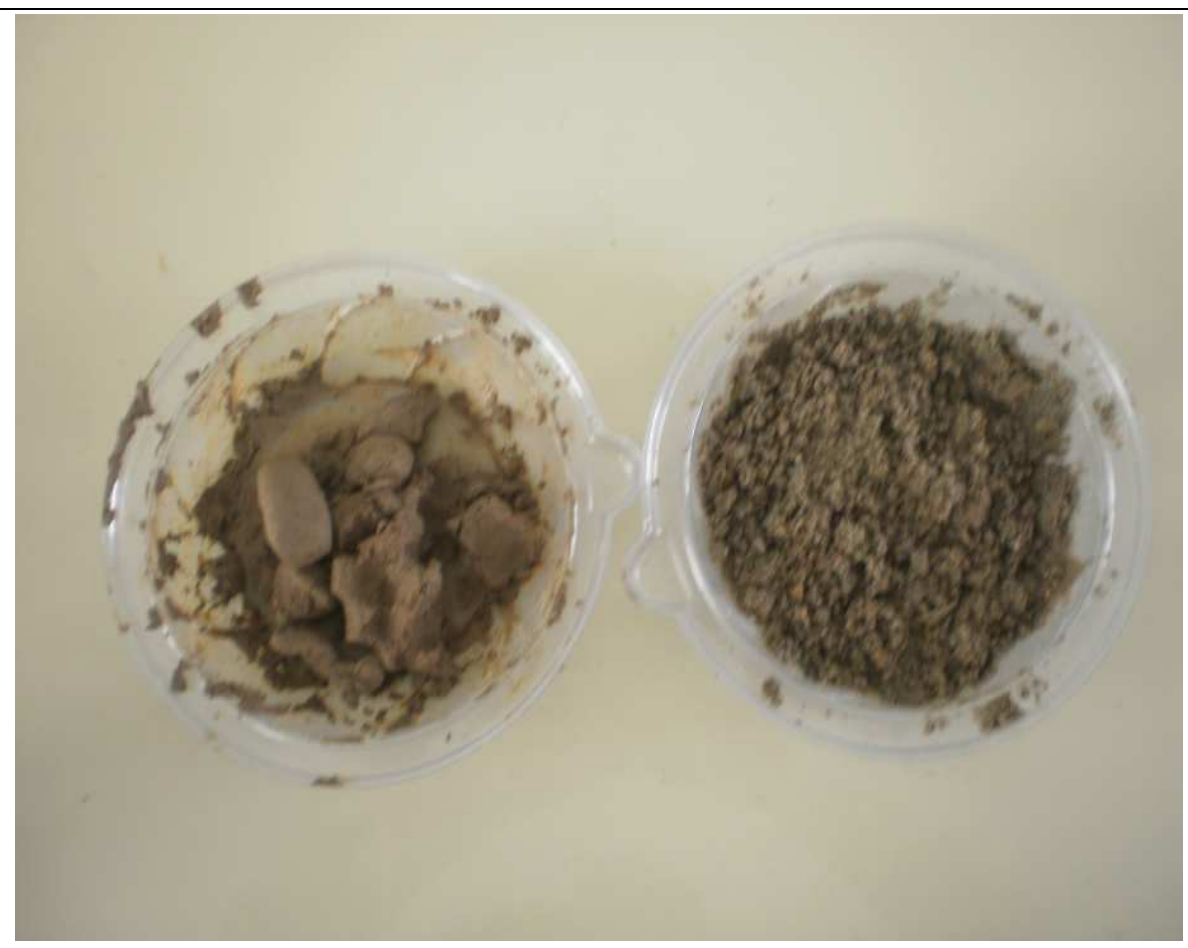

Figura 3. Solos produzidos pelos alunos. Fonte: Atividade prática, 2014.

Depois da atividade os alunos foram capazes de responder por meio de perguntas orais, quais os elementos que estavam presentes na formação do solo. As respostas foram: água, ar, organismos, areia, argila e minerais, entre outros. Alguns alunos comentaram ainda, sobre a importância de preservar o solo numa perspectiva ambiental para as gerações futuras, fortalecendo a ideia de desenvolvimento sustentável para o equilíbrio da vida na terra. A professora da turma destacou que a atividade foi de fundamental importância para a abordagem do conteúdo e que não seria capaz de chegar aos mesmos resultados se o conteúdo fosse dado apenas no livro didático por meio de aulas meramente expositivas.

Planejar uma aula de geografia, assim como as das demais disciplinas, não é uma tarefa simples. Antes de tudo é preciso "conhecer a organização do espaço geográfico e o funcionamento da natureza em suas múltiplas relações, de modo a compreender o papel das sociedades em sua construção e na produção do território, da paisagem e do lugar". (BRASIL, 2001, p. 121). Nesse sentido, é fundamental que os professores tenham um melhor aproveitamento do tempo de estudo, desenvolvendo ações e práticas que permitam trabalhar conceitos voltados para o cotidiano do aluno, utilizando os diferentes recursos a favor da aprendizagem. A função do solo para os seres vivos deve ser trabalhada a partir dos anos iniciais, onde os alunos sejam capazes 
de "observar, registrar e comunicar algumas semelhanças e diferenças entre diversos ambientes, identificando a presença comum de água, seres vivos, luz, calor, solo e características especificas dos ambientes" (BRASIL, 1997, p. 46).

Os professores devem desenvolver o interesse pelos primeiros contatos dos alunos em relação ao tema, mas para isso, é necessário que eles estejam familiarizados com o mesmo. Para Pontuschka (2009, p. 96): “Ocorre que, para o professor poder cumprir esse objetivo, é imprescindível que ele mesmo tenha aprendido e seja capaz de dominar a habilidade de produzir pesquisa". Nesse sentido, a ação prática visou contemplar os dois campos de estudos, a universidade e a escola, tendo em vista que os estudantes do curso de geografia atuarão na escola em suas múltiplas atividades. $\mathrm{O}$ estudo de solos torna-se importante nos anos iniciais quando desenvolvido com o apoio de atividades que permitam aos alunos reconhecerem a importância desse elemento para a vida e o equilíbrio do planeta. Para Curi, et al. (1993, p. 74): “O Solo é material mineral e/ou orgânico consolidado na superfície da terra que serve como um meio natural para o crescimento e desenvolvimento de plantas terrestres". È necessário estudar o solo pela sua capacidade e utilidade na produção de alimentos e na conservação dos ecossistemas. Desde cedo à humanidade já utilizava o solo como um recurso fundamental a sobrevivência. Com o inicio da agricultura o homem foi aprendendo que algumas terras eram mais produtivas que outras (Lepsch, 2002). Esse fato levou os seres humanos a se fixarem em locais que disponibilizavam melhores condições de vida, permitindo melhor adaptação ao lugar. $\mathrm{Na}$ atualidade o uso intensivo dos recursos naturais tem exposto o planeta aos desequilíbrios da relação causada pelos seres humanos e a natureza. È de fundamental importância despertar a atenção para a importância do solo e os perigos da sua degradação, uma vez que o meio ambiente funciona como um sistema integrado em que a ação errônea sobre uma das partes, causa consequências ao todo. As atividades práticas em sala de aula além de auxiliar na aprendizagem do conteúdo constitui um importante meio de investigação, uma vez que novos questionamentos podem ser levantados, estimulando a prática da pesquisa. Essas ações devem ser levadas ao cotidiano dos alunos, sejam das escolas ou das universidades, para que eles também desenvolvam suas habilidades de investigar determinados processos, retirando deles o que lhe será útil para o conhecimento e as experiências de vivência. 


\section{CONSIDERAÇÕES FINAIS}

Apesar dos problemas ainda presentes na educação brasileira, é possível desenvolver métodos e técnicas que possibilitem ao educador, trabalhar a realidade e a importância dos diversos elementos no cotidiano do aluno. Porém a falta de materiais didáticos é justificativa para a não realização de atividades práticas, tornando o livro didático como único recurso, realizando-se apenas leituras e escritas sobre os temas. Quanto à geografia, o número de aulas semanais reservadas pelos professores para o seu ensino, em alguns casos são insuficiente para uma aprendizagem significativa, se fazendo necessário reconhecer a geografia com a mesma importância que as demais disciplinas escolares. A realização de Práticas experimentais nos cursos de licenciatura constitui uma ferramenta importante, porque permitem aos alunos, aprenderem novas abordagens do conteúdo que poderão ser realizadas em sala de aula e contribuírem com um melhor aprendizado. Com a realização do Experimento os alunos foram capazes de identificar a textura dos solos arenoso e argiloso, bem como, citar alguns elementos que estão presente na fração do solo como ar, água, areia, matéria orgânica e rochas, ou seja, elementos presentes do dia-a-dia, nada distante do seu conhecimento, para que os alunos tenha uma melhor compreensão de que o solo é essencial na existência da vida é preciso que o conheça para que possa ser defensores do ambiente em que vive, pois os recursos naturais estão sendo degradados, agravando ainda mais os problemas sociais e ambientais. A análise dos solos produzidos em sala de aula pelos alunos possibilitou que os mesmos compreendessem o conteúdo sobre solos, de forma dinâmica e interativa, tornando-os capazes de identificar os diferentes elementos que compõem o solo e a sua importância para os seres vivos e a sociedade, numa perspectiva ambiental em detrimento das medidas de sustentabilidade. Portanto, para que tenhamos uma educação de qualidade teremos que ter pessoas compromissadas a ensinarem e aprender. Pois, na maioria dos casos a culpa fica na responsabilidade da A ou de B, mas para que possa dá qualidade à educação, todos os indivíduos envolvidos: alunos, professores, escola, família, comunidade, ou seja, todas as instâncias dentro ou fora do espaço escolar devem mostrar interesse em mudar o ensino, aderindo às novas metodologias. 


\section{REFERÊNCIAS}

BRASIL. Secretaria de Educação Fundamental. Parâmetros Curriculares Nacionais: ciências naturais. Brasília: MEC/SEF, 1997.

Secretaria de Educação Fundamental. Parâmetros Curriculares Nacionais:

história e geografia. $3^{\circ}$ ed. Brasília: MEC/SEF, 2001.

CAVAlCANTI, Lana de Sousa. Geografia e Prática de Ensino. Goiana: Alternativa, 2002, p. 17.

CURI, Nilton; LARACH, Jorge Olmos Iturri; KAMPF, Nestor; MUNIZ, Antônio Carlos \& FONTES, Luiz Eduardo Ferreira. Vocabulário de Ciências do Solo. Campinas: Sociedade Brasileira de Ciência do Solo, 1993, p.64, 75.

LEPSCH, Igo. F. Formação e conservação dos solos. São Paulo: Oficinas de Textos, 2002 .

MACANHÃO, Priscila. \& LIMA, Marcelo Ricardo. Experimentoteca de solos conhecendo a composição do solo e suas diferentes texturas. Projeto solo na escola. Paraná: Departamento de solos e engenharia agrícola da UFPR, 2005.

OLIVEIRA, Ariovaldo Umbelino de. Educação e Ensino de Geografia na Realidade Brasileira. In: Para onde vai o ensino de Geografia? ed.7. São Paulo: Contexto, 1998. p. $135-144$.

PONTUSCHKA, Nídia Nacib. Para ensinar e aprender geografia. $3^{\circ}$ ed. São Paulo: Cortez, 2009.

SACRAMENTO, Ana Claudia Ramos. Didática e Educação Geográfica: algumas notas. UNI Pluri/Versidad. 2010, p.05. vol.10, n.3, Version Digital. 